\title{
Content analysis of medical students' seminars: a unique method of analyzing clinical thinking
}

\author{
Yukari Takata ${ }^{1}$, Gerald H Stein ${ }^{2 *}$, Kuniyuki Endo ${ }^{3}$, Akiko Arai ${ }^{4}$, Shun Kohsaka ${ }^{5}$, Yuka Kitano ${ }^{6}$, Hitoshi Honda', \\ Hidetaka Kitazono ${ }^{8}$, Hironobu Tokunaga ${ }^{9}$, Yasuharu Tokuda ${ }^{10}$, Mikako Obika $^{11}$, Tomoko Miyoshi ${ }^{12}$, \\ Hitomi Kataoka ${ }^{12}$ and Hidekazu Terasawa ${ }^{9}$
}

\begin{abstract}
Background: The study of communication skills of Asian medical students during structured Problem-based Learning (PBL) seminars represented a unique opportunity to assess their critical thinking development. This study reports the first application of the health education technology, content analysis (CA), to a Japanese web-based seminar (webinar).

Methods: The authors assigned twelve randomly selected medical students from two universities and two clinical instructors to two virtual classrooms for four PBL structured tutoring sessions that were audio-video captured for CA. Both of the instructors were US-trained physicians. This analysis consisted of coding the students' verbal comments into seven types, ranging from trivial to advanced knowledge integration comments that served as a proxy for clinical thinking.

Results: The most basic level of verbal simple responses accounted for a majority (85\%) of the total students' verbal comments. Only $15 \%$ of the students' comments represented more advanced types of critical thinking. The male students responded more than the female students; male students attending University 2 responded more than male students from University 1. The total mean students' verbal response time for the four sessions with the male instructor was 6.9\%; total mean students' verbal response time for the four sessions with the female instructor was 19\% ( $p<0.05)$.

Conclusions: This report is the first to describe the application of CA to a multi-university real time audio and video PBL medical student clinical training webinar in two Japanese medical schools. These results are preliminary, mostly limited by a small sample size $(n=12)$ and limited time frame (four sessions). CA technology has the potential to improve clinical thinking for medical students. This report may stimulate improvements for implementation.
\end{abstract}

Keywords: Problem-based learning, Communication measurement, Clinical thinking development

\section{Background}

Learning clinical thinking is a complex task of accumulating knowledge and experience [1-3]. For medical students entering clinical training, PBL and its variations offer an entry into this complex world [4,5]. Small group discussions centered on a patient's narrative with history, physical examination and laboratory data compromise the data, summarized as the problem list, for the discussion to extract meaningful concepts leading to diagnosis and management, loosely defined as clinical thinking.

\footnotetext{
* Correspondence: jerrydoc@ufl.edu

${ }^{2}$ Department of Medicine and Veterans Affairs Medical Center, University of Florida College of Medicine, Gainesville, Florida, USA

Full list of author information is available at the end of the article
}

An essential component of the case discussion is the verbal communication among the students and their instructor.

Instruments to measure small group speaking as evolved a technique called content analysis (CA). CA was developed for product marketing and heath education. Borg and Gall [6] defined CA as "a research technique for the objective, systematic, and quantitative description of the manifest content of communication". CA includes student length of speaking, participate rates, social clues, interactions, speech content to name a few of the possible measurements $[7,8]$. Very few medical educational CA applications have been reported [9]. A partial use of CA was explored in a recent study of the audio

\section{Biomed Central}

(C) 2013 Takata et al.; licensee BioMed Central Ltd. This is an open access article distributed under the terms of the Creative Commons Attribution License (http://creativecommons.org/licenses/by/2.0), which permits unrestricted use, distribution, and reproduction in any medium, provided the original work is properly cited. 
analysis of the 'morning report' of new case admissions coding the interactions between supervisors and their residents [10].

Furthermore Asian students and by inference, Japanese medical students, are particularly unaccustomed to classroom discussion, especially when led by older faculty [11]. Their hindrances include dependency and respect for authority, cultural inhibition to be silent and lack of training to ask questions that broadly include development of problem solving skills. Yet PBL requires talking as a means to learn clinical thinking [12]. Although Japanese medical education has undergone recent structural changes, little has been reported on the outcome of these changes [13]. PBL has become increasing used in Japanese medical education $[14,15]$. This report is the first to use CA to document medical students' verbal responses as part of a Japanese multi-university PBL webinar developmental project.

\section{Methods}

Content analysis of students' verbal responses during eight webinar PBL tutoring sessions was examined.

\section{Participants}

The study involved two US-trained clinical instructors (one female, one male) and 12 fifth year Japanese medical students (four female, eight male). The instructors were selected for their three years of general internal medicine training in the United States and their JapaneseEnglish bilingual skills. Six randomized medical students from each of two distant Japanese medical universities were randomly assigned to one of the two instructors' two virtual 'classrooms' (http://www.webex.co.jp). The study protocol specified that each instructor led four tutoring sessions (1.5 hours each) over the course of four weeks. The topics and teaching materials were standardized and designed as a syllabus by a panel of Japanese \& American medical educators to promote PBL. The instructors received minimal communication skills to enhance learning; no PBL training or feedback or standardization occurred during the four tutoring sessions. All tutoring sessions had video and audio components captured for the subsequent CA. The students' identity was masked for this analysis. All 12 students signed a detailed informed consent form.

\section{Code book}

A CA code book to analyze the verbal interactions during the tutoring sessions.

An underlying assumption of communication $\mathrm{CA}$ is that dialogues are representative of underlying cognitive processes [8].

The level of critical thinking expressed by students was coded using a modified version of Practical Inquiry
Model (PIM), which characterizes phases of practical inquiry through descriptors and indicators [8]. For example, the model's second phase, Exploration, is characterized through "inquisitive" communication, which is often indicated through suggestions for consideration and brainstorming. Exploration is then followed by integration and resolution to complete the model's phases of practical inquiry.

The PIM was organized into the code book through a series of trial coding sessions, performed by health educator coders. The coding sessions comprised analysis of speech descriptors and indicators. After the code book was finalized, an inter-coder reliability test of 19 responses, or about $10 \%$, of all comments, involving only the variables open to interpretation, resulted in a Krippendorff's alpha of 0.80 , above the 0.75 considered acceptable [16]. Each students' response for one of seven possible types, which essentially scaled the responses' level of critical thinking, was coded independently by the health educator coders (Table 1). The respondent's identity, audience, and position (i.e. whether they were the inquisitor or respondent) were also coded. The coding authors made the type critique from watching the captured recordings of the webinars; they coded all responses and comments that the students made. They made no distinction between responses and comments.

\section{Statistical analyses}

Proportions and percentages between groups were compared using by chi-square test. Two-tailed $p$ values less than 0.05 were considered as statistical significance. All statistical analysis was performed using SPSS-J version 20 (Tokyo, Japan).

\section{Results}

All students' comments, except for those related to technical issues and social commentary at the beginning and

\section{Table 1 Critical thinking response types}

\begin{tabular}{|c|c|}
\hline $\begin{array}{l}\text { Response } \\
\text { types }\end{array}$ & Details of response types \\
\hline T1 & Simple phrase responses, based on rote memory \\
\hline $\mathrm{T} 2$ & $\begin{array}{l}\text { Response has more depth that Type } 1 \text { but still based on } \\
\text { rote memory, includes because, if, when, etc. }\end{array}$ \\
\hline T3 & Response to "How would you ask a patient____? \\
\hline T4 & $\begin{array}{l}\text { Response shows integration - combines ideas to form } \\
\text { new meanings (analytical) }\end{array}$ \\
\hline T5 & $\begin{array}{l}\text { Response shows advanced integration - combines } \\
\text { knowledge from multiple and/or obscure sources to } \\
\text { introduce original ideal solutions (potentially novel to } \\
\text { instructor as well) }\end{array}$ \\
\hline T6 & Spontaneous questions directed to instructor \\
\hline T7 & $\begin{array}{l}\text { Social commentary, greetings, appreciation, etc., } \\
\text { unrelated to tutored topic }\end{array}$ \\
\hline
\end{tabular}


end of each session, were included in the analysis. Descriptive statistics were primarily used to characterize interactions observed in this study.

The total mean students' verbal response time for the four sessions with the male instructor was $6.9 \%$; total mean students' verbal response time for the four sessions with the female instructor was 19\% (Table 2). The total mean student response time for the four sessions with the male instructor was significantly lower than that with female instructor $(\mathrm{p}<0.05)$.

Total students' comments with both instructors were 458 comments. Of the total comments, responses involving the most basic level of critical thinking (T1) accounted for over half of the comments $(66 \%, n=302)$. The second level of critical thinking (T2) also accounted for the second most common response type at $15 \%(n=69)$. Notably, the more advanced levels of critical thinking (T4 and T5), which the PBL project was striving to achieve, represented just $4 \%$ of all comments $(n=9)$ with no $\mathrm{T} 5$ 's being represented.

Because the numbers of advanced levels of critical thinking responses were small, we combined the type of responses as follows: 'simple responses' type 1, 2 and 7; 'advanced thinking responses' types 3 to 5 , and spontaneous topic-related questions directed to the instructor type 6 -two non topic related questions were deleted (Table 3).

'Simple responses', having no comments about the syllabus topics, comprised $85 \%$ of the response types, 'advanced thinking responses' contained $11 \%$, and topicrelated spontaneous questions were $4 \%$ for a total of $15 \%$ more advanced types of critical thinking directly related to the syllabus topics (Figure 1).

Examining the distribution of combined comments type for each session suggested that students' comments generally decreased as time passed, giving little indication that critical analysis increased across time (Figure 2).

In another analysis we combined types 1,2 and 7 as 'expanded simple responses' and types 3 to 5 as 'integration thinking'. Total comments made by students' sex were proportionally represented with female students $(\mathrm{n}=4)$ accounting for $33.0 \%(\mathrm{n}=142)$ and male students $(\mathrm{n}=8)$ accounting for $67.0 \%(\mathrm{n}=278)$ (Figure 3$)$.

Table 2 Total students' minutes response times

\begin{tabular}{lccc}
\hline & Male instructor & Female instructor & p value \\
\hline Session 1 & $5.3 / 91(5.8)$ & $13.4 / 94(14.1 \%)$ & 0.14 \\
Session 2 & $8.2 / 93(8.8)$ & $20.0 / 80(25)$ & 0.02 \\
Session 3 & $4.5 / 78(5.6)$ & $17.3 / 90(19.2)$ & 0.06 \\
Session 4 & $6.6 / 91(7.2)$ & $18.2 / 102(17.8)$ & 0.11 \\
\hline
\end{tabular}

Total students' minutes response times divided by total session time in minutes with the percent students response times in parenthesis. The total mean student response time for the 4 sessions with the male instructor was significantly lower than that with female instructor $(p<0.05)$.
Table 3 Combined critical thinking response types

\begin{tabular}{|c|c|}
\hline Response types & Details of response types \\
\hline \multirow{3}{*}{$\begin{array}{l}\text { Simple- Types 1, } 2 \\
\text { and } 7\end{array}$} & Simple phrase responses, based on rote memory \\
\hline & $\begin{array}{l}\text { Response has more depth that Type } 1 \text { but still } \\
\text { based on rote memory, includes because, if, } \\
\text { when, etc. }\end{array}$ \\
\hline & $\begin{array}{l}\text { Social commentary, greetings, appreciation, etc., } \\
\text { unrelated to tutored topic }\end{array}$ \\
\hline \multirow[t]{3}{*}{$\begin{array}{l}\text { Advanced thinking } \\
\text { Types 3-5 }\end{array}$} & $\begin{array}{l}\text { Response to "How would you ask a } \\
\text { patient__? ?" }\end{array}$ \\
\hline & $\begin{array}{l}\text { Response shows integration - combines ideas to } \\
\text { form new meanings (analytical) }\end{array}$ \\
\hline & $\begin{array}{l}\text { Response shows advanced integration - combines } \\
\text { knowledge from multiple and/or obscure sources } \\
\text { to introduce original ideal solutions (potentially } \\
\text { novel to instructor as well) }\end{array}$ \\
\hline Type 6 & $\begin{array}{l}\text { Spontaneous topic-related questions directed to } \\
\text { instructor }\end{array}$ \\
\hline
\end{tabular}

There was no statistical difference between male and female students $(\mathrm{p}=0.69)$.

Students instructed by the female instructor also commented significantly more than those under the tutorage of a male instructor, with the female instructor's group contributing $60.0 \%$ of comments $(n=275)$.

We observed minor differences between the two medical universities, with University 2 students contributing more responses, regardless of their instructors (Figure 4). There was no statistical difference between students of University 1 and those of University $2(\mathrm{p}=0.92)$.

\section{Discussion}

We presented the first CA of medical students' webinars. This is a unique application of the CA technique that was developed for health educators, to medical student seminars. The most basic level of simple responses

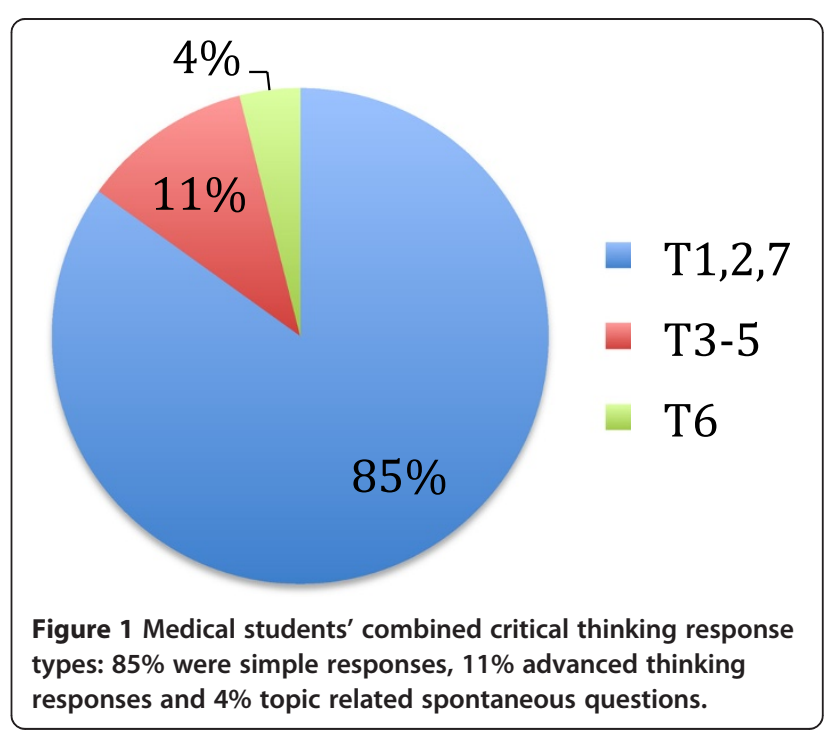




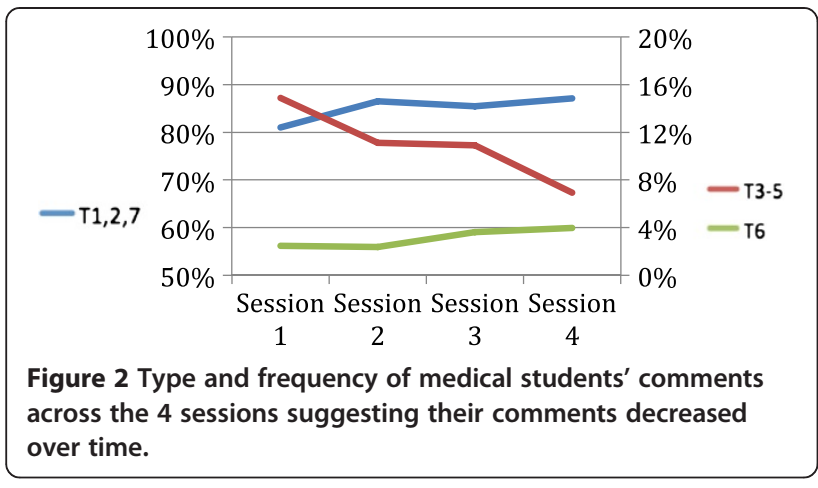

having no comments about the syllabus topics, accounted for a majority (85\%) of the total students' comments. Only $15 \%$ of the students' comments represented more advanced types of critical thinking.

It was anticipated that data would show improved clinical thinking as measured by Types 3 to 5 changes. Such was not the case. In part the total talking time of the students was very low, much lower than anticipated, with no change over the four sessions. Conversely the dominant talking time of the instructors implied they reverted to the traditional practice of lecturing, perhaps because they lacked skills to promote discussion.

Usual communication skills training and assessment of medical students center on interactions and feedback from standardized actor patients- objective structured clinical examination (OSCE) $[17,18]$. A two-day instructional communication skills report showed $5^{\text {th }}$ grade Japanese medical students' marginal improvement using OSCE [19].

However, in medical educational communities where prior educational exposure has attenuated student responses, the seminar experiences requiring verbal interactions may be necessary before adequate doctor-patient communication skills develop.

Limiting factors of this study were small sample size, short interval for discussions and small number of sessions (four). We had envisioned a larger medical student sample size. However sample size was limited by the

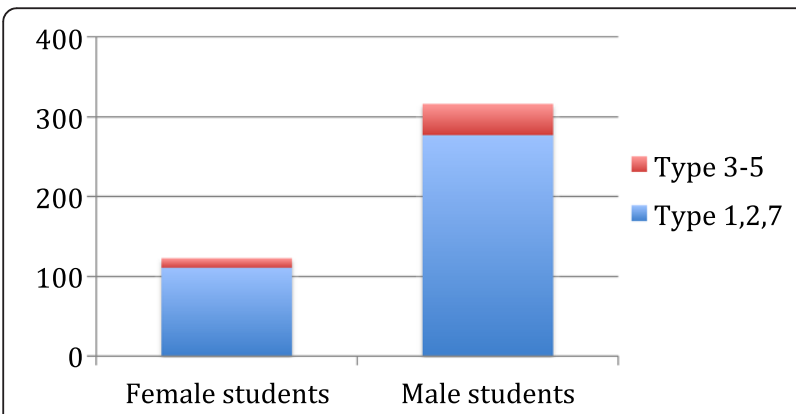

Figure 3 Distribution and number of comments by males and females were not statistically different.

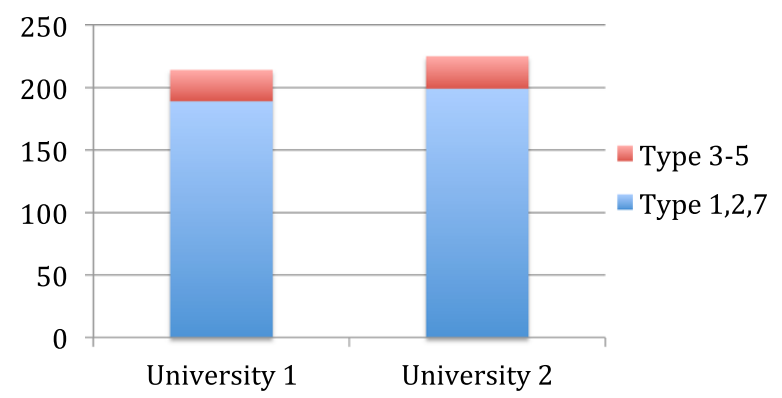

Figure 4 Distribution and number of comments by the universities were not statistically different.

coordination problems expressed by several Japanese medical universities to participate. The duration of the study and small number of sessions were restricted by the tutors' already too busy daily workloads.

There are many possible reasons for the short times of students' advanced thinking responses. For the instructors their possible reasons were: 1) the instructors were not trained to teach PBL. PBL faculty development with practice including instant feedback, is not offered in Japanese medical universities; 2) Completion of a US residency does not provide adequate PBL coaching for medical students, a major criteria for instructor selection in our study; 3) The authors provided no inter-session improvement feedback; 4) The instructors likely felt compelled to complete the seminars' syllabus, thinking it was more important than student participation; and 5) If the total number of tutored sessions had been increased to eight sessions over eight weeks, it is possible more critical thinking responses would have been observed.

For the students their possible reasons for their short times of advanced thinking responses were: 1) The students lacked prior long term educational experiences in verbal problem solving exercises; 2) Their usual ways of classroom learning has been limited to large hall lectures, a usual cultural norm; 3) The presence of a faculty member has been an inhibiting influence since silence shows respect to one's elders; 4) An Asian student does not verbally challenge the instructor; 5) Speaking out has been considered culturally rude [11,12]; 6) The lack of familiarity with the tutors and relatively limited four sessions likely inhibited the students' responses as suggested in a recent report [20].

Although the tutoring sessions did not appear to increase expression of PBL understanding over time, the students' sex may have play a role in critical thinking. Within the scope of our very limited data, although the male students responded more, female students expressed proportionally more upper-level critical thinking than their male counterparts; the female instructor's group also contributed significantly more comments, suggesting that Japanese women, who traditionally have been observed to 
be more expressive and nurturing may find it easier to grasp PBL concepts. However, these data were limited to verbal expressions; it may not be a fair representation of true levels of cognitive activity.

Also, that University 2 students generally commented more than University 1 students, suggested local medical education styles may influence students' respond in web-tutoring sessions. Specifically University 2 actively promotes PBL by having faculty use their PBL teaching methods acquired during PBL workshops at an American medical school, and by encouraging students to participate in their popular extra-curricular PBL club. University 1 does not offer PBL faculty development or PBL clubs. However several clinical departments at University 1 offer PBL training to their postgraduate trainees.

Nonetheless, the application of CA, from the field of health and nutrition education, has the potential to make important contributions to improving clinical thinking skills, in both Western and non-Western medical universities.

Furthermore, detailed evaluation of faculty and student performance during small group seminars, CA may be ideally suited for this task given its many year multidisciplinary history [20-23]. Our report builds on the large number of CA studies in the scientific and educational literature. For example the nursing and nutritional health literatures are enriched by many CA studies [24-27]. Recent applications of CA include marketing drugs to women [28], and designing nutritional educational materials [29]. In the current milieu of interdisciplinary education, the inclusion of health and nutritional students and faculty, the groups actively using CA, have not been highlighted [30,31]. Also recent medical educator physician critics of PBL [32] and PBL defenders [33] may find benefit from applying CA to PBL seminars.

Based upon this analysis, future studies with more adequate instruction, larger sample sizes, and with longer duration may be able to demonstrate that CA be a universal instrument to study the impact and improvements of PBL on training medical students in clinical thinking.

\section{Conclusions}

In conclusion CA was applied to a multi-university real time PBL medical student clinical training webinar. Although the results are preliminary, mostly limited by the small sample size and short duration of the study, the CA technology may have the potential to improve PBL training for medical students; the challenges presented here warrant further investigation.

\section{Ethical approval}

Ethical approval for educational studies and surveys is not required according to national practice in Japan. However, the study adhered to ethical principles, and the respondents are not identifiable from the data.

\section{Abbreviations}

PBL: Problem-based learning; CA: Content analysis; Webinar: Web-based seminar; PIM: Practical inquiry model; OSCE: Objective structured clinical examination.

\section{Competing interests}

The authors declare that they have no competing interests.

\section{Authors' contributions}

YT conceived of the study and designed the coding tables; GHS, KE and YTakata drafted the manuscript, KE, AA and YTokuda collected, coded and analyzed the data; SK, YK, HH, HK, HTokunaga MO, TM, HK and HTerasawa participated in the design and coordination of the medical students and technical recordings. All authors read and approved the final manuscript.

\section{Authors' information}

Yukari Takata is a senior evaluation specialist at IQ Solutions in Rockville, Maryland. She recently received the $\mathrm{PhD}$ in health education and mass communications at the College of Journalism and Communications, University of Florida, Gainesville, Florida, USA.

Gerald H. Stein is a Clinical Assistant Professor at the Department of Medicine, School of Medicine, University of Florida, Gainesville, Florida, and a Physician Consultant at the Clinic of Jurisdiction, Veteran Affairs Medical Center, Gainesville, Florida, USA.

Kuniyuki Endo is a staff physician at the Department of Neurology, Nagoya Daini Red Cross Hospital, Nagoya, Aichi, Japan.

Akiko Arai is a candidate for the PhD at the College of Health and Human performance, University of Florida, Gainesville, Florida, USA.

Shun Kohsaka is an Assistant Professor at the Department of Cardiology, School of Medicine, Keio University, Tokyo, Japan.

Yuka Kitano is an Assistant Professor at the Department of, Emergency Medicine and Critical Care Medicine, School of Medicine, St. Marianna University, Kawasaki, Kanagawa, Japan.

Hitoshi Honda is an Attending Physician and consultant, Departments of General Internal Medicine and Infectious Diseases, Teine Keijinkai Medical Center, Sapporo, Hokkaido, Japan.

Hidetaka Kitazono is an Attending Physician and consultant, Departments of General Internal Medicine and Infectious Diseases Tokyo Bay Medical Center, Noguchi Hideyo Memorial Noguchi International Hospital, Urayasu, Chiba, Japan.

Hironobu Tokunaga MD, is an Assistant Professor at the Department of Emergency Medicine, University of Fukui Faculty of Medical Sciences, Fukui, Japan.

Yasuharu Tokuda, MD, MPH, is a Professor at the Institute of Clinical Medicine, Graduate School of Comprehensive Human Sciences, University of Tsukub, School of Medicine, Tsukuba, Japan.

Mikako Obika, MD, is an Assistant Professor at the Center for Graduate Medical Education, Okayama, Okayama University Medical School, Japan. Tomoko Miyoshi, MD, is a Professor at the Department of Medical Education and Primary Care, Okayama University Medical School, Okayama, Japan. Hitomi Kataoka, MD, is a Professor at the Department of Medical Education and Primary Care, Okayama University Medical School, Okayama, Japan. Hidekazu Terasawa, MD, is a Professor at the Department of Emergency Medicine, University of Fukui Faculty of Medical Sciences, Fukui, Japan.

\section{Acknowledgements}

Funding/Support: Japanese Ministry of Education, Culture, Sports, Science and Technology Grant 23590870

We thank the fifth year medical students from University of Fukui Faculty of Medical Sciences, Japan and Okayama University Medical School, Japan, for their participation.

\section{Author details}

${ }^{1}$ University of Florida College of Journalism and Communications, Gainesville, Florida, USA. ${ }^{2}$ Department of Medicine and Veterans Affairs Medical Center, University of Florida College of Medicine, Gainesville, Florida, USA. ${ }^{3}$ Nagoya Daini Red Cross Hospital, Nagoya, Japan. ${ }^{4}$ University of Florida College of Health and Human Performance, Gainesville, Florida, USA. ${ }^{5}$ Keio University School of Medicine, Tokyo, Japan. ${ }^{6}$ St Marianna University School of

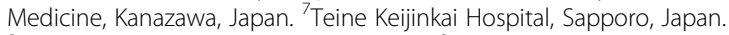
${ }^{8}$ Noguchi Bayside Hospital, Chiba, Japan. ${ }^{9}$ Department of Emergency 
Medicine, University of Fukui Faculty of Medical Sciences, Fukui, Japan. ${ }^{10}$ Institute of Clinical Medicine, Graduate School of Comprehensive Human Sciences, University of Tsukuba School of Medicine, Mito, Ibaraki, Japan. ${ }^{11}$ Center for Graduate Medical Education, Okayama University Medical School, Okayama, Japan. ${ }^{12}$ Department of Medical Education and Primary Care, Okayama University Medical School, Okayama, Japan.

Received: 2 April 2013 Accepted: 25 November 2013

Published: 1 December 2013

\section{References}

1. Eva K: What every teacher needs to know about clinical reasoning. Med Educ 2004, 39:98-106.

2. Ark T, Brooks L, Eva K: Giving learners the best of both worlds: do clinical teachers need to guard against teaching pattern recognition to novices? Acad Med 2006, 81:405-409.

3. Rencic J: Twelve tips for teaching expertise in clinical reasoning. Med Teach 2011, 33(11):887-892.

4. Miflin B, Campbell C, Price D: A conceptual framework to guide development of self-directed, lifelong learning in problem-based medical curricula. Med Educ 2000, 34:299-306.

5. Wood $D$ : $A B C$ of learning and teaching in medicine. Problem based learning. BMJ 2003, 326:328-330.

6. Borg W, Gall M: The methods and tools of observational research. In Educational research: an introduction. 5th edition. Edited by Borg W, Gall M. London: Longman; 1989:473-530.

7. Hara N, Bonk C, Angeli C: Content analysis of online discussion in an applied educational psychology course. Instr Science 2000, 28:115-152.

8. Garrison D, Anderson T, Archer W: Critical thinking, cognitive presence and computer conferencing in distant education. Am J Dist Educ 2001, 15(1):7-23.

9. De Grave WS, Boshuizen HP, Schmidt HG: Problem based learning: cognitive and metacognitive processes during problem analysis. Instr $\mathrm{SCi}$ 1996, 24:321-341.

10. Goldszmidt M, Aziz N, Lingard L: Taking a detour: positive and negative effects of supervisors' interruptions during admission case review discussions. Acad Med 2012, 87(10):1-7.

11. Khoo H: Implementation of problem-based learning in Asian medical schools and students' perceptions of their experience. Med Educ 2003, 37:401-409.

12. Inada H, Mitsunami K, Motohara S, Fetters M: Increasing motivation of medical students through a participatory style of learning: a case study demonstrating how to move away from 'osmotic learning. Med Educ (Japan) 2010, 41(5):347-351.

13. Teo A: The current state of medical education in Japan: a system under reform. Med Educ 2007, 41:302-308.

14. Rao H: Perspectives in medical education 5. Implementing a more integrated, interactive and interesting curriculum to improve Japanese medical education. Keio J Med 2007, 56:75-85

15. Rao H, Rao K: Perspectives in medical education 9. Revisiting the blueprint for reform of medical education in Japan. Keio J Med 2010, 59(2):52-63.

16. Wimmer R, Dominick J: Mass Media Research: An Introduction. 6th edition. Belmont, California: Wadsworth; 2000:154.

17. Rees C, Sheard C, McPherson A: Communication skills assessment: the perceptions of medical students at the University of Nottingham. Med Educ 2002, 36:868-878.

18. Windish D, Eboni G, Clever S, Magaziner J, Thomas P: Teaching medical students the Important connection between communication and clinical Reasoning. J Gen Intern Med 2005, 20:1108-1113.

19. Mukohara K, Kitamura K, Wakabayashi H, Abe K, Sato J, Ban N: Evaluation of a communications skills seminar for students in a Japanese medical school: a non-randomized controlled study. BMC Med Educ 2004 4:24. http://www.biomedcentral.com/1472-6920/4/24

20. Hauer KE, O'Brian BC, Hansen LA, Hirsh D, Ma IH, Ogur B, Poncelet AN, Alexander EK, Teherani A: More is better: students describe successful and unsuccessful experiences with teachers differently in brief and longitudinal relationships. Acad Med 2012, 87(10):1-8.

21. Prober CG, Heath C: Lecture halls without lectures - A proposal for medical education. N Eng J Med 2012, 366(18):1657-1659.
22. Rice K, Zwarenstein M, Conn LG, Kenaszchuk C, Russell A, Reeves S: An intervention to improve interprofessional collaboration and communication: a comparative qualitative study. J Interprof Care 2010, 24(4):350-361

23. Riesenberg LA, Little BW, Wright V: Nonphysician medical educators: a literature review and job description resource. Acad Med 2009, 84(8):1078-1088

24. Graneheim UH, Lundman B: Qualitative content analysis in nursing research: concepts, procedures and measures to achieve trustworthiness. Nurs Educ Today 2004, 24:105-112.

25. Elos $\mathrm{S}$, Kyngas $\mathrm{H}$ : The qualitative content analysis process. J Adv Nurs 2008, 62(1):107-115.

26. Kondrack NL, Wellman NS, Amundson D: Content analysis: review of methods and their applications in nutrition education. J Nutr Educ Behav 2002, 34:224-230.

27. Levis DM, Westbrook $\mathrm{K}$ : A content analysis of preconception health education materials: characteristics, strategies, and clinical-behavioral components. Amer J Health Promo 2013, 27(3s):s36-s42.

28. Sokol J, Wackowski O, Lewis MJ: Marketing pharmaceutical drugs to women in magazines: a content analysis. A J Health Behav 2010, 34(4):402-411.

29. Hernández-Garbanzo Y, Griffin S, Cason KL, Loberger G, Williams J, Baker S, Coffee A, Linton B, Hall T, Hayden V: A content analysis of nutrition education curricula used with low-income audiences: implications for questionnaire development. Health Promot Pract 2013, 14(4):534-542.

30. WHO publication: Interprofessional collaborative practice in primary health care: nursing and midwifery perspectives. Hum Resour Health Obs 2013(13). http://www.who.int/hrh/resources/observer13/en/index.html.

31. Dyrbye LN, Starr SR, Thompson GB, Lindor KD: A model for integration of formal knowledge and clinical experience: the advanced doctoring course at Mayo Medical School. Acad Med 2011, 86(9):1130-1136.

32. Onyon C: Problem-based learning: a review of the educational and psychological theory. Clin Teach 2012, 9:22-26.

33. Schmidt H, Muijtjens A, Cees P, Van der Vleuten C, Norman G: Differential student attrition and differential exposure mask effects of problem-based learning in curriculum comparison studies. Acad Med 2012, 87(4):2012.

doi:10.1186/1472-6920-13-156

Cite this article as: Takata et al:: Content analysis of medical students' seminars: a unique method of analyzing clinical thinking. BMC Medical Education 2013 13:156.

\section{Submit your next manuscript to BioMed Central and take full advantage of:}

- Convenient online submission

- Thorough peer review

- No space constraints or color figure charges

- Immediate publication on acceptance

- Inclusion in PubMed, CAS, Scopus and Google Scholar

- Research which is freely available for redistribution 